\title{
Isotretinoína: perfis farmacológico, farmacocinético e analítico
}

\author{
Danielle Guimarães Almeida Diniz', Eliana Martins Lima' ${ }^{2 *}$ Nelson Roberto Antoniosi Filho'
}

${ }^{1}$ Instituto de Química, Universidade Federal de Goiás, ${ }^{2}$ Faculdade de Farmácia, Universidade Federal de Goiás

*Correspondência:

E. M. Lima

Faculdade de Farmácia

Universidade Federal de Goiás

Praça Universitária c/1ª Avenida

Qd 62

74.610-220 - Goiânia - GO.

E-mail: emlima@farmacia.ufg.br
A isotretinoina, quimicamente conhecida como ácido-13-cisretinóico, faz parte do amplo grupo de compostos relacionados à vitamina A. É empregada particularmente no tratamento da acne cística e nodular e como inibidor da proliferação de células neoplásicas, por exercer efeito regulador sobre a diferenciação celular. Os efeitos adversos envolvendo o uso de isotretinoina estão relacionados à pele e membranas mucosas, sistemas nervoso, músculo esquelético, linfático, gastrintestinal, cardiorespiratório e geniturinário. A isotretinoína é um composto termo e fotossensivel e, por assim se apresentar, desperta o interesse pelo estudo de sua estabilidade, empregando-se para isso várias metodologias analíticas como a CLAE, CG, análise térmica, espectroscopia de massa, microcalorimetria, difratometria de raios-X e muitas outras que devem ser selecionadas de acordo com o interesse do pesquisador.

\author{
Unitermos: \\ - Isotretinoína \\ - CLAE \\ - Estabilidade química \\ - Usos terapêuticos \\ - Efeitos adversos
}

\section{INTRODUÇÃO}

O filósofo grego Hipócrates de Cós (460-377 a.c.) e o explorador escocês David Livingstone (1813-1873) já relatavam a existência de afecções visuais e epiteliais que poderiam ser curadas com a administração de fígado bovino cru. Entretanto, os conhecimentos então disponíveis ainda não permitiam atribuir tais afecções à carência de vitamina $\mathrm{A}$, cuja relação com uma deficiência nutricional só foi reconhecida definitivamente no século XIX (Marcus, Coulston, 1996).

Funk, em 1912, sugeriu o termo vitamina para denominar um grupo de fatores essenciais para as atividades fisiológicas e que estão presentes nos alimentos. Posteriormente, foi evidenciada a existência de mais de um grupo destes fatores, os quais foram classificados por McCollum em 1913, em fator lipossolúvel A e fator lipossolúvel B.
A estrutura molecular da vitamina A foi determinada em 1931 por Karrer e colaboradores que propuseram o nome de axeroftol para a mesma, baseado na ação preventiva da vitamina A contra a xeroftalmia, uma afecção caracterizada pelo ressecamento e espessamento da conjuntiva. Wald (1934) isolou da retina animal uma substância por ele denominada de retinina. Mortom, em 1944, afirmou que este composto era um aldeído da vitamina $\mathrm{A}$ e o denominou de retinaldeído ou retinal (Gundersen, Blomhoff, 2001; IUPAC (http://www.chem.qmw.ac.uk/ iupac/misc/ret.html)).

As recomendações para a nomenclatura das vitaminas, incluindo retinol, retinal e ácido retinóico, foram publicadas pela União Internacional de Química Pura e Aplicada (IUPAC) em 1960 e posteriormente revisadas em 1965 (IUPAC-IUB, 1966; IUPAC-IUB, 1983).

O conhecimento da estrutura molecular da vitamina 
A foi o marco inicial para a procura por derivados químicos e sintéticos com atividade biológica do retinol. Sporn e colaboradores introduziram o termo retinóide em 1976<smiles>CC1=C(/C=C/C(C)=C/C=C/C(C)=C/CO)C(C)(C)CCC1</smiles>

Vitamina A<smiles>CC1=C(/C=C/C(C)=C/C=C/C(C)=C\C(=O)O)C(C)(C)CCC1</smiles>

Ácido 13-cis-retinóico (Isotretinoína)<smiles>CC1=C(/C=C/C(C)=C/C=C/C(C)=C\C(=O)O)C(C)(C)CCC1O</smiles>

Ácido-13-cis-4-hidroxiretinóico<smiles>CC1=C(/C=C/C(C)=C/C=C/C(C)=C\C(=O)O)C(C)(C)CCC1=O</smiles>
retinóico<smiles>CC1=C(/C=C/C(C)=C/C=C/C(C)=C\C(=O)O)C(C)(C)C(O)CC1=O</smiles>

Ácido-13-cis-2-hidroxi4-oxo-retinóico para abranger todos os análogos estruturais naturais, bem como os sintéticos da vitamina A (Figura 1) (Sporn, et al. 1976).<smiles>CC1=C(/C=C/C(C)=C/C=C/C(C)=C/C(=O)O)C(C)(C)CCC1</smiles>

\section{Ácido todo-trans-retinóico} (Tretinoína)<smiles>CC(/C=C/C12OC1(C)CCCC2(C)C)=C\C=C\C(=O)O</smiles>

Ácido todo-trans-5,6-epoxi-5,6diidro-retinóico
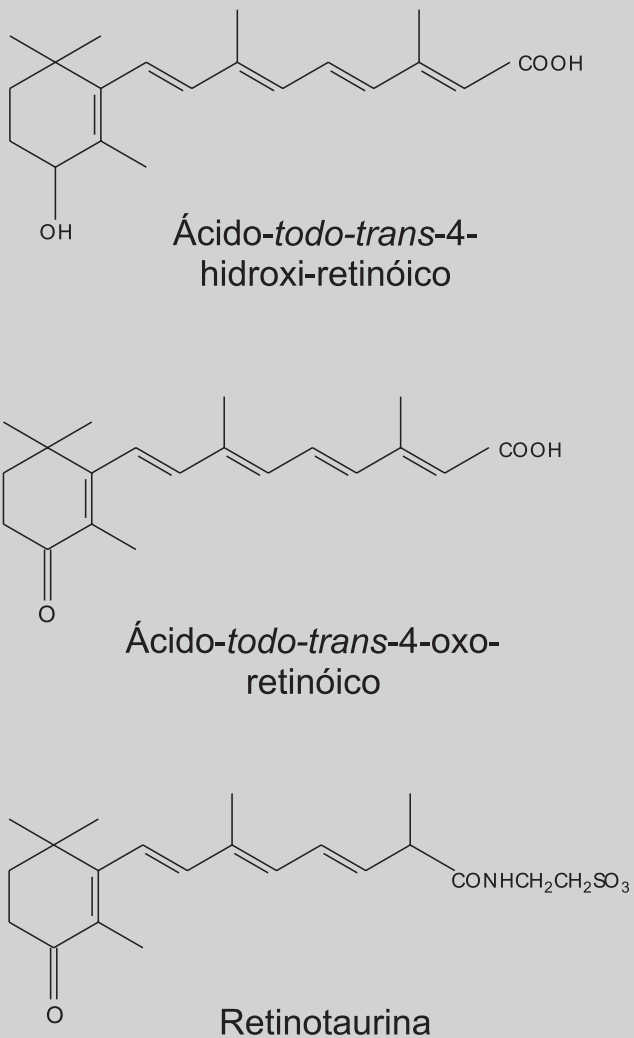

FIGURA 1 - Estrutura molecular de retinóides. 
De acordo com a definição da IUPAC e da União Internacional de Bioquímica e Biologia Molecular (IUB), retinóides é o termo empregado para designar uma classe de compostos cuja estrutura química consiste em quatro grupos isoprenóides unidos de modo cabeça-cauda. O esqueleto dos retinóides naturais é constituído por um anel não aromático de seis átomos de carbono com uma cadeia lateral poliprenóide que é, com poucas exceções, terminada com um grupo funcional constituído de carbono e oxigênio. O metabolismo e o catabolismo dos retinóides provocam o rearranjo destas três partes estruturais do esqueleto dos retinóides justificando a existência de vários análogos com efeitos biológicos potencialmente diversos (IUPAC-IUB, 1983; Gundersen, Blomhoff, 2001).

Sporn e Roberts sugeriram, em 1985, que os retinóides fossem definidos como uma classe de substâncias que pode iniciar uma resposta biológica pela ligação e ativação de um receptor específico ou um conjunto de receptores. Entretanto, o mecanismo de ação destes compostos permaneceu desconhecido até 1987, quando foram descobertos receptores nucleares para o ácido retinóico (Giguere et al., 1987; Petkovich et al., 1987; Brand et al., 1988; Umesono et al., 1988; Mangelsdorf et al., 1990; Mangelsdorf et al., 1991; Levin et al., 1992). Os receptores para o ácido retinóico, identificados como membros de uma superfamília de receptores intranucleares, atuam como fatores de transcrição ligante-dependentes, sendo ativados pelos isômeros e metabólitos do ácido retinóico. Estes receptores foram classificados em RAR $\alpha, \beta, \gamma \mathrm{e}$ $\mathrm{RXR} \alpha, \beta, \gamma$ com base em diferenças entre os aminoácidos que compõem sua estrutura, resposta frente aos diferentes retinóides e habilidade em modular a expressão de genes específicos (Mangelsdorf et al., 1990; Manglesdorf et al., 1991; Heyman et al., 1992; Boehm et al., 1994).

O ácido todo-trans-retinóico liga-se com afinidade semelhante aos três tipos de receptores RAR (Heyman et al., 1992; Levin et al., 1992; Chandraratna, 1996). Por outro lado, o ácido 9-cis-retinóico apresenta elevada afinidade para ligação a ambos os grupos de receptores RAR e RXR. Entretanto, ainda não se pode afirmar que o ácido 9-cis-retinóico seja o ligante fisiológico para RXR (Kitareewan et al., 1996; Napoli, 1999), uma vez que outros metabólitos do retinol também agem como ligantes que ativam fatores de transcrição nesta família de receptores e ainda, os ácidos todo-trans-retinóico,9-cisretinóico e 13-cis-retinóico são isômeros geométricos, podendo sofrer interconversão in vivo (Chandraratna, 1996; Klaassen et al., 1999).

Os retinóides estão envolvidos na proliferação e diferenciação de vários tipos celulares durante o desenvolvimento fetal e também ao longo da vida, como resultado da ativação do complexo retinóide-receptor (Sporn, Roberts, 1985). Por outro lado, a ativação deste complexo pode bloquear a ação de outros fatores de transcrição como o AP1, cuja expressão mostra-se exacerbada em várias condições hiperproliferativas e inflamatórias (Nagpal et al., 1995; Chandraratna, 1996).

Como resultado dos mecanismos de ação genômica e não genômica dos retinóides, seus diferentes efeitos biológicos são dependentes da expressão dos receptores específicos, do tipo e concentração dos compostos retinóides presentes na célula, da expressão das proteínas de ligação e das enzimas responsáveis pelo metabolismo dos retinóides in vivo e in vitro (Klaassen et al., 1999; Napoli, 1999).

Considerando a evolução histórica de cada composto retinóide, Allen e Bloxham sugeriram em 1989 a classificação dos retinóides em três grupos ou gerações. A primeira geração de compostos compreende o retinol (vitamina A) e os compostos derivados de seu metabolismo, como a tretinoína (ácido todo-trans-retinóico) e a isotretinoína (ácido 13-cis-retinóico). A segunda geração compreende os análogos sintéticos da vitamina A com uma parte da molécula modificada para produzir compostos que apresentam somente parte do perfil farmacológico da vitamina A. Os principais representantes desta geração são o etretinato e a acitretina. Na terceira geração de compostos a molécula base da vitamina A é extensamente modificada com a perspectiva de selecionar uma atividade biológica específica da vitamina A, produzindo um fármaco com atividade biológica seletiva e com efeitos adversos mínimos. Os retinóides da terceira geração são altamente potentes e possuem dois anéis aromáticos que restringem a flexibilidade da cadeia lateral. Esta classe de retinóides tem sido denominada de arotenóides (Allen, Bloxham, 1989; Marcus, Coulston, 1996; Marcus, Coulston, 2001) (Figura 2).

Entre os retinóides naturais e sintéticos avaliados para uso em humanos, somente a isotretinoína é capaz de promover significativa remissão da acne (Farrel et al., 1980; Saurat, 1997). O ácido todo-trans-retinóico também apresenta a capacidade de inibir a secreção sebácea e, embora seu uso via oral no tratamento da acne tenha demonstrado menor eficiência do que o tratamento com uso oral do ácido 13-cis-retinóico, seu emprego no tratamento tópico da acne é bastante difundido (Hommel et al., 1996; Saurat, 1997).

Apesar de possuir vários dos efeitos farmacológicos da vitamina A, a aplicação terapêutica do ácido todotrans-retinóico via oral é bastante limitada também devido aos intensos efeitos colaterais de hipervitaminose, os quais ocorrem mesmo em concentrações terapêuticas. $\mathrm{O}$ 


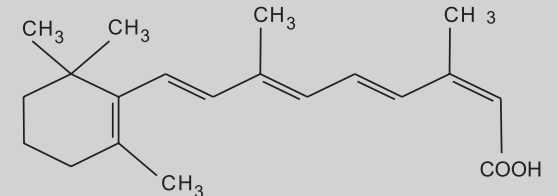

Ácido 13-cis-retinóico (Isotretinoína)

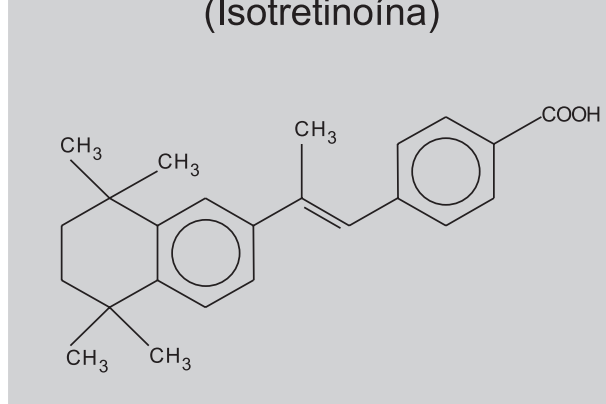

RO 13-7410

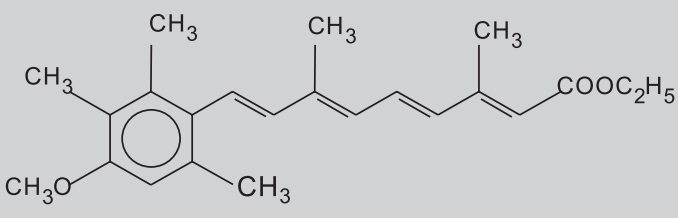

Etretinato

FIGURA 2 - Comparação entre a estrutura do ácido 13-cis-retinóico e de compostos sintéticos do ácido retinóico.

uso oral de tretinoína é restrito a casos de leucemia promielocítica aguda (APL) em pacientes refratários ou intolerantes aos regimes citotóxicos de quimioterapia e apenas como fármaco de segunda escolha (Warrel et al., 1991; FDA 2002 (www.fda.gov/cder)). Entretanto, este tratamento requer acompanhamento e suporte médico intensivo, já que, além dos efeitos adversos comuns aos retinóides, cerca de $25 \%$ dos pacientes em uso de tretinoína desenvolvem a chamada síndrome do ácido retinóico-APL (RA-APL), caracterizada por febre, dispnéia, aumento de peso e presença de infiltrado pulmonar. Esta síndrome ocorre geralmente no primeiro mês de tratamento, sendo fatal em vários casos (Warrel et al., 1991; Roche, 2002 (www. rocheusa.com)).

Por este motivo, a isotretinoína é considerada o único retinóide natural (composto da primeira geração de retinóides) que apresenta aplicação clínica através de terapia sistêmica para tratamento de acne (Allen, Bloxham, 1989; Hommel et al., 1996; Saurat, 1997). A isotretinoína demonstra grande eficiência terapêutica relacionada à indução e controle da diferenciação epitelial, nos tecidos secretores de muco ou queratinizantes, à produção de prostaglandinas $\mathrm{E}_{2}$, de colágeno, de precursores da queratina, como os tonofilamentos e tonofibrilas, e ao controle da proliferação de Propionibacterium acne. Uma vez que o desenvolvimento das glândulas sebáceas e a exacerbação de sua atividade secretora são fatores essenciais para a ocorrência de lesão inflamatória associada à acne, o bloqueio na produção de sebo provocado pela isotretinoína constitui fator determinante de sua atividade farmacológica no tratamento desta afecção (Allen, Bloxham, 1989; Fonseca, Prista, 1993; Saurat, 1997; AHFS-Drug information, 1998; OMS, 1999; Drugdex, 2001).

\section{USOS TERAPÊUTICOS}

A isotretinoína é empregada, com particular interesse, no tratamento da acne cística e nodular (Saurat, 1997) e em outros tipos de afecções cutâneas (como por exemplo, pitiríase rubra, queratose e lúpus eritematoso), de forma experimental (Marcus, Coulston, 1996; White, 1999; Drugdex, 2001). A acne é uma enfermidade inflamatória dos folículos pilossebáceos da face, das costas e tórax cuja expressão clínica é dependente de vários fatores. Habitualmente aparece na puberdade, quando a estimulação androgênica promove a hiperprodução de sebo, com hiperqueratinização folicular, colonização por bactérias gram-positivas (Propionibacterium acne) e inflamação local. As bactérias Propionibacterium acne provocam uma resposta inflamatória através da síntese de substâncias extracelulares, como lipases, proteases, hialuronidases e fatores quimiotáticos (Tolman, 1992; OMS, 1999). Do ponto de vista clínico, a intensidade da acne varia desde as formas mais leves, em que existem poucos comedões (cistos pilossebáceos dilatados que contêm sebo, epitélio queratinizado, bactérias e leveduras saprófitas), às formas graves e desfigurantes que formam 
nódulos e fístulas com intensa reação inflamatória. A cicatrização ocorre seguida da formação de quelóides, sobretudo em pacientes da raça negra(Bulengo-Ransby et al. 1993; OMS, 1999).

Considerando que as cicatrizes da acne nodular grave constituem um importante problema de aceitação social, a enfermidade deve sempre ser tratada em sua fase inicial. O tratamento farmacológico é dirigido para inibir a secreção de sebo, a queratinização folicular e a inflamação. Em casos moderados, são utilizados com freqüência antibióticos orais, estrogênios e antiandrogênios e retinóides, sendo estes últimos, reservados aos casos graves e resistentes (OMS, 1999; White, 1999).

O uso oral de 0,6 a $0,75 \mathrm{mg} / \mathrm{kg} /$ dia de isotretinoína por 16 a 35 semanas produz excelente resposta em $90,4 \%$ dos pacientes com acne vulgar. Estes resultados foram comprovados por Al-Kahawajan em 1996, em um grupo de pacientes dos quais $56 \%$ apresentavam acne moderada resistente à terapia convencional e 14\% apresentavam acne cística nodular, sendo que em ambos os casos houve completa remissão da doença.

Em razão de sua atividade sobre a proliferação e diferenciação celular, os retinóides têm demonstrado eficácia na terapia antineoplásica de lesões pré-malígnas da mucosa oral, e a isotretinoína é eficaz na prevenção da ocorrência de tumores secundários no trato digestivo e respiratório superior em pacientes com carcinoma de células escamosas na cabeça e pescoço. Além disso, a isotretinoína também apresenta efeito inibidor da carcinogênese em modelos experimentais com animais de laboratório e em culturas de células, inibindo também a proliferação de várias linhagens de células neoplásicas, como por exemplo, células de leucemia mielóide, melanoma, adenocarcinoma mamário e leucemia linfocítica (Sporn et al.,1976; Harisiadis et al. ,1978; Lotan, 1980; Lotan et al.,1980; Breitman et al.,1981).

Comprovando esta atividade dos retinóides, Breitman e colaboradores demonstraram, em 1981, que em cultura de células de leucemia promielocítica humana, o ácido retinóico em concentração de $1 \mathrm{mmol}$ foi capaz de promover a diferenciação celular em níveis próximos a $100 \%$. Ainda segundo estes autores, a isotretinoína e o ácido todo-trans-retinóico (tretinoína) exercem atividade semelhante. Warrel et al. (1991) propuseram a dose oral de $45 \mathrm{mg} / \mathrm{kg} /$ dia de tretinoína como sendo capaz de promover a indução da diferenciação celular na leucemia promielocítica aguda.

O perfil farmacocinético da isotretinoína é análogo ao da vitamina A. Após administração oral, o pico de concentração plasmática da isotretinoína é atingido em cerca de 2 a 4 horas. Aproximadamente $20 \%$ da isotretinoína são absorvidos quando administrada com estômago vazio, aumentando para $40 \%$ quando em presença de alimento (Nankervis, 1995; White, 1999; Marcus, Coulston, 2001). Isotretinoína e tretinoína são interconvertidas in vivo, e cerca de $20 \%$ a $30 \%$ da dose de isotretinoína são aparentemente metabolizados nesta rota. O principal metabólito da isotretinoína é a 4-oxo-isotretinoína que é excretada pela bile após ser conjugada com o ácido glicurônico, possuindo meia-vida média de eliminação de 25 horas. Com a administração repetida, a concentração de equilíbrio é estabelecida em 5 a 7 dias (Brazzell, Colburn, 1982; AHFS- Drug information, 1998; Marcus, Coulston, 2001).

Estudos farmacocinéticos realizados em animais recebendo doses orais de isotretinoína marcada indicam que esta substância lipofílica possui distribuição tissular de 15 minutos com máximo de 1 hora e declínio até níveis não detectáveis em um período de 24 horas em muitos tecidos, tais como o hepático, renal, ovariano, adrenal e glândulas lacrimais (Allen, Bloxham, 1989; AHFS-Drug information, 1998; Drugdex, 2001). A isotretinoína é excretada pela via urinária, sendo possível detectar na urina a presença de quantidades baixas de isotretinoína não conjugada. Entretanto, a excreção de cerca de 53 a $74 \%$ da isotretinoína administrada ocorre nas fezes, como resultado de uma absorção incompleta, eliminação biliar ou recirculação enteroepática (Allen, Bloxham, 1989).

O principal uso terapêutico da isotretinoína é ainda no tratamento de acne grave e resistente às terapias convencionais. Com este objetivo, a dosagem terapêutica varia de 0,5 a $2 \mathrm{mg} / \mathrm{kg} / \mathrm{dia}$ por 16 a 24 semanas (Allen, Bloxham, 1989; Martindale, 1996; White, 1999; Drugdex, 2001).

\section{EFEITOS ADVERSOS}

A maioria dos efeitos adversos envolvendo o uso de retinóides, inclusive a isotretinoína, está relacionada à pele e membranas mucosas, sistema nervoso, músculoesquelético, hematopoiético e linfático, gastrintestinal, cardiorespiratório e geniturinário. Por ser altamente teratogênica, quando administrada no primeiro trimestre de gestação, a isotretinoína pode ocasionar abortos espontâneos ou má formação do feto, sendo estes efeitos também observados quando a gestação ocorre dentro de quatro meses após o término do tratamento (Bigby, Stern, 1988; Lebowitz, Berson, 1988; White, 1999).

As reações adversas envolvendo o sistema nervoso central apresentam-se na forma de cefaléias severas, pseudotumor cerebral (papiloedema e/ou aumento da pressão do fluido cerebroespinhal), depressão, diminuição da libido, impotência, insônia e, em alguns casos, foi re- 
latada reação semelhante à provocada pelo dissulfiram após a ingestão de etanol (Bigby, Stern, 1988; Lebowitz, Berson, 1988; Martindale, 1996; Drugdex, 2001).

Várias reações adversas envolvendo a pele e membranas mucosas puderam ser comprovadamente atribuídas à isotretinoína, como urticária e eritema multiforme. Outras reações como hiperpigmentação, distrofia ungueal e reações vasculares também foram observadas com o uso de isotretinoína (Bigby, Stern, 1988; AHFS-Drug information, 1998; Drugdex, 2001).

Efeitos adversos relacionados aos sistemas hematopoiético e linfático incluem leucopenia, aumento da taxa de sedimentação dos eritrócitos, diminuição da concentração da hemoglobina e ainda agranulocitose e episódios de sangramento, principalmente em pacientes com hemofilia A (Bigby, Stern, 1988; Allen, Bloxham, 1989; Drugdex, 2001).

Cerca de $25 \%$ dos pacientes em tratamento com isotretinoína apresentam elevação do nível plasmático de triglicérides, o que, em alguns casos, pode estar associado ao aparecimento de pancreatite aguda. A isotretinoína pode provocar ainda uma leve queda da concentração plasmática de HDL colesterol e aumento de LDL e VLDL colesterol. As alterações nos níveis séricos de triglicérides e colesterol são reversíveis com a interrupção do tratamento. Reações adversas menos freqüentes incluem naúseas, vômitos, sangramentos gastrintestinais, anorexia, perda de peso e colite ulcerativa (Bigby, Stern, 1988; McCarter, Chen, 1992; Barth et al., 1993; Drugdex, 2001).

Entre os efeitos oculares freqüentemente observados, encontram-se conjuntivite, cataratas, distúrbios visuais, opacidade da córnea e decréscimo da visão noturna, além de fotossensibilidade (Lebowitz, Berson, 1988). Efeitos adversos envolvendo o sistema geniturinário incluem proteinúria, hematúria, hiperuremia, uretrite e desordens menstruais, tais como amenorréia e menorragia (Bigby, Stern, 1988; AHFS-Drug information, 1998; Drugdex, 2001).

De modo semelhante ao que ocorre com muitos outros fármacos que apresentam toxicidade elevada, a encapsulação dos retinóides (inclusive da isotretinoína) em vesículas lipídicas (lipossomas) foi capaz de promover a redução de seus efeitos tóxicos e a otimização de seus efeitos terapêuticos (Parthasarathy, Mehta, 1998).

\section{SÍNTESE QUÍMICA}

Apesar de sua grande utilidade terapêutica, a isotretinoína não é ainda produzida no Brasil, estando os laboratórios dependentes de importação da matéria-prima.

Quimicamente, a síntese da isotretinoína decorre de uma reação de condensação de produtos olefínicos. A condensação pode levar a uma mistura de estereoisômeros com predominância da forma isomérica 11,13-di-cis, porém, também, com produção de isômeros trans (Boschetti et al., 1996).

A forma isomérica 13-cis é sinteticamente obtida por técnicas diferentes que incluem a condensação com adição de um metal de transição como catalisador, preferencialmente o paládio, e isomerização regiosseletiva por substituição na dupla ligação 11 -cis, separando-se os isômeros por cristalização. Outro método empregado na conversão do produto 11,13-di-cis em 13-cis consiste no emprego da irradiação de luz natural à temperatura ambiente com presença de foto ativador. Nestas condições reacionais, o produto desejado surge no reator na forma de um precipitado (Boschetti et al., 1996).

O Laboratório MAG (Milão, Itália), em 1999, patenteou o processo de síntese e separação da isotretinoína sem o uso de metais de transição em uma das etapas do processo, iniciando com vinil-beta-ionol preparado da ionona e haleto de vinil magnésio, e obtendo um produto com alta pureza e estabilidade. $\mathrm{O}$ uso de metais de transição como ródio e paládio para promover isomerização do ácido 11,13 di-cis retinóico não somente apresenta custo elevado como, também, dificulta a separação do ácido 13-cis-retinóico (Laboratorio MAG Pat.MI98A1093). A presença de traços de sais metálicos e, mais freqüentemente, sais de metais de transição no ácido 13-cis-retinóico é, não somente, um contraste com o critério de pureza requerido, como também, um fator contribuinte para a instabilidade do produto, evidenciada por Tan e colaboradores, em 1992.

No organismo o ácido retinóico e derivados são formados no interior dos enterócitos e células alvo a partir do retinol (vitamina A) através de um processo oxidativo dividido em duas vias. Algumas isoenzimas da álcool desidrogenase $(\mathrm{ADH})$ possuem a capacidade de oxidar o retinol (um álcool) em retinal (um aldeído), enquanto isoenzimas da aldeído desidrogenase (ALDH) e da retinal desidrogenase $(\mathrm{RDH})$ oxidam o retinal em ácido retinóico (Duester, 1996; Napoli, 1999).

\section{ESTABILIDADE}

O curto prazo de validade apresentado pela isotretinoína depende, aparentemente, das condições de temperatura e armazenamento (Singh, Bakshi, 2000). Estudos sobre a estabilidade da isotretinoína por métodos de microcalorimetria, espectrometria de massas, cromatografia líquida de alta eficiência (CLAE) e cristalografia revelaram a ocorrência de modificações físicas e químicas nas características do produto em razão de exposição ao oxigênio atmosférico, luz, umidade e al- 
tas temperaturas (Tan et al., 1992; Tan et al., 1993; Berbenni et al., 2001).

Os estudos cristalográficos da estrutura do ácido retinóico e seus isômeros demonstraram a existência de diferentes formas geométricas dos cristais entre os compostos. Na ausência de oxigênio o produto sofre apenas mudanças físicas com o decorrer do tempo. A decomposição dos compostos na presença de ar atmosférico resulta em grande número de produtos, originados principalmente da interrupção oxidativa do sistema conjugado de dupla ligação. O estágio de degradação depende da pressão parcial de oxigênio, sendo acelerado com a presença de luz e altas temperaturas, e ocorre sem nenhuma seletividade por uma dupla ligação em particular. $\mathrm{O}$ aparecimento de componentes amorfos está diretamente relacionado à existência de um processo oxidativo que muda a estrutura molecular, induzindo uma perda parcial do empacotamento cristalino (Malpezzi et al., 1998).

De acordo com Stam e McGillavry (1963) e Stam (1972), uma forma tricíclica do ácido retinóico pode ser obtida pelo aquecimento a $120^{\circ} \mathrm{C}$ em relação à forma monocíclica. A forma monocíclica é menos estável e, no entanto, é obtida à temperatura ambiente (Berbenni et al., 2001).

Tan e colaboradores (1992) examinaram a estabilidade da tretinoína e da isotretinoína por técnicas de microcalorimetria e CLAE. Já Berbenni e colaboradores (2001), empregaram técnicas de análise térmica (Calorimetria Exploratória Diferencial - DSC, Termogravimetria - TG, Termogravimetria acoplada a Infravermelho com Transformado de Fourrier - TG/FTIR) e espectroscopia (FTIR com refletância difusa, UV-visível, espectrometria de massas e difratometria de raios-X) para a determinação da estabilidade térmica e a caracterização físico-química da tretinoína e isotretinoína. Através de exame calorimétrico diferencial (DSC) foi demonstrado que a isotretinoína funde a $180{ }^{\circ} \mathrm{C}$, enquanto a tretinoína funde antes, demonstrando um pico endotérmico a $150{ }^{\circ} \mathrm{C}$, podendo apresentar transição de forma monocíclico-tricíclico.

Para a extração e isolamento dos retinóides são utilizadas principalmente as técnicas de extração em fase sólida (SPE) e extração por fluido supercrítico (SFE). O processo de extração da isotretinoína e seus fotoisômeros é descrito tanto para fluidos biológicos quanto para cremes, géis, cápsulas e micropartículas usando técnicas de fluido supercritico ou extração em fase sólida (Simmons et al., 1997; Gatti et al., 2000). As vantagens da extração com fluido supercrítico encontram-se no isolamento da isotretinoína a partir do plasma e de várias formas farmacêuticas, sem a exposição da amostra à luz durante a extração, maior velocidade de separação e ausência de des- perdício de solventes, em contraste com outras técnicas clássicas de extração (Simmons et al., 1997).

Apesar de ter sido a técnica de extração mais empregada para a análise de isotretinoína e dos retinóides de maneira geral, a SPE utilizando como fase sólida materiais de sílica modificada, não é a técnica de extração mais adequada para esta classe de compostos, já que este tipo de extração requer o pré-condicionamento do cartucho de extração, o emprego de grande volume de solvente, maior tempo de extração e, posterior eluição com solventes polares. No caso de compostos instáveis como os retinóides, o número de etapas do processo de extração pode favorecer sua degradação. Entretanto, quando o sistema SPE-CLAE está on-line, o analito é eluido diretamente para a coluna, diminuindo parcialmente o número de etapas do processo (Gundersen et al., 1997). Em casos de isolamento da isotretinoína de matrizes plasmáticas, a SPE é uma técnica adicional para a concentração e purificação do fármaco após a precipitação das proteínas (Eckhoff, Nau, 1990; Gundersen, Blomhoff, 2001).

\section{ANÁLISE CROMATOGRÁFICA}

A cromatografia sempre representou a técnica analítica preferida para a análise dos retinóides e a CLAE tornou-se, paulatinamente, o método analítico predominante para a separação e quantificação dos retinóides, tanto em amostras biológicas quanto em formas farmacêuticas. Ao todo, há um vasto número de retinóides naturais e sintéticos com diferentes polaridades e o desenvolvimento de um método analítico que possa separar todos os retinóides, em somente uma análise cromatográfica, tem demonstrado ser uma tarefa muito difícil. Deste modo, as condições cromatográficas são muitas vezes elaboradas para cada aplicação analítica pretendida (Gundersen, Lundanes, Blomhoff, 1997; Gundersen, Blomhoff, 2001).

Várias condições cromatográficas foram testadas para a determinação simultânea dos compostos retinóides e separação dos 4-oxo-metabólitos, utilizando diferentes solventes em diferentes porcentagens, em condições isocráticas ou em gradiente de eluição, assim como em fase normal e em fase reversa.

Técnicas de CLAE-EM-EM (cromatografia líquida de alta eficiência acoplada a detectores de massas) também foram empregadas para a quantificação e identificação dos níveis plasmáticos da isotretinoína. Tal procedimento tem sido eficiente quando os compostos em estudo apresentam instabilidade térmica ou quando não são voláteis para serem analisados por CG-EM (cromatografia gasosa acoplada a espectrômetro de massas) (Bempong et al., 1995; Lehman, Franz, 1996). 
Entretanto, Oyler e colaboradores (1989), Lehman e Malany (1989) e Eckhoff e Nau (1990) conseguiram caracterizar a isotretinoína e seus produtos de degradação empregando CG-EM. Lehman e Malany (1989) e Eckhoff e Nau (1990) utilizaram tanto técnicas de cromatografia líquida quanto técnicas de cromatografia gasosa para a análise de isotretinoína.

Lehman e Malany (1989) empregaram CG-EM para comprovar os picos de eluição designados para a isotretinoína e tretinoína por CLAE. Todas as amostras demonstraram correspondência com os tempos de eluição obtidos por CG e CLAE. Eckhoff e Nau (1990) investigaram a presença endógena dos ácidos todo-trans e 13-cisretinóico e dos ácidos todo-trans-4-oxo-retinóico e 13-cis4-oxo-retinóico no plasma humano empregando três sistemas analíticos de CLAE e um sistema CG-DSM-MIS (cromatografia gasosa acoplada a espectrometria de massas no modo de monitoramento de íons selecionados). O primeiro sistema de CLAE foi designado para a análise de amostras de plasma; o segundo sistema analítico de CLAE foi utilizado para nova análise cromatográfica dos analítos coletados no primeiro sistema. O terceiro sistema analítico de CLAE foi utilizado para a análise cromatográfica dos derivados metilados do ácido retinóico. A cromatografia gasosa, neste caso, foi utilizada adicionalmente para comparação e identificação dos componentes da amostra com os compostos de referência.

Utilizando somente a técnica de CLAE acoplada a um detector ultravioleta e/ou a um detector de fluorescência, vários autores como Wyss e Bucheli (1992 e 1997), Lefebvre et al. (1995), Disdier et al. (1996), Tan et al. (1993), Gatti et al. (2000 e 2001) também identificaram os retinóides e seus produtos de degradação.

Wyss e Bucheli utilizaram, em 1992, a CLAE com gradiente e associação de coluna. Em 1997, estes mesmos autores relacionaram a mudança de coluna com a detecção em ultravioleta; Disdier e colaboradores utilizaram, em 1996, a CLAE com fase móvel isocrática e com gradiente de eluição testando várias composições de fases móveis; Tan e colaboradores (1993) e Gatti e colaboradores (2000 e 2001), utilizando CLAE com detector ultravioleta, demonstraram as curvas de degradação e as características autocatalíticas de cada isômero.

Wang e Wang, em 2001, desenvolveram um método de CLAE com detector eletroquímico para quantificação da isotretinoína, tretinoína e da vitamina $\mathrm{A}$, bem como do acetato de tocoferol, do retinil acetato e do retinol em formas farmacêuticas. O processo de eletroautoxidação, aplicado para quantificação e determinação simultânea dos retinóides, demonstrou estar de acordo com os resultados obtidos por CLAE-UV. A CLAE acoplada a um detector eletroquímico é um método tanto seletivo quanto sensível para monitoramento dos retinóides e pode ser aplicado a uma variedade de situações clínicas que necessitam de exatidão para pesquisa de retinóides, tanto no plasma quanto em formas farmacêuticas (Sakhi et al. 1998; Oliveira, Watson, 2001; Wang, Wang, 2001).

A CLAE-EM-EM demonstrou vantagens para caracterização dos retinóides devido à identificação dos fragmentos de massa do ácido retinóico, naturais e sintéticos. Este método permite avaliar os níveis endógenos de ácido retinóico e o doseamento do fármaco para estudos de farmacocinética (Lehman, Franz, 1996).

Devido à fotolabilidade, à sensibilidade ao calor e à oxidação dos retinóides, sua determinação quantitativa em formas farmacêuticas é particularmente importante para o controle de qualidade do produto final e para os ensaios indicativos de estabilidade (Gatti et al., 2000). Brisaert e Plaizer-Vercammer (2000) demonstraram que é grande a fotodegradação da tretinoína em loção, frente a uma lâmpada de xenônio, e que este processo também pode originar diferentes isômeros com diferentes atividades biológicas. Muitos aditivos como tensoativos, ciclodextrinas e filtros UV falharam na fotoproteção do medicamento. Entretanto, além de investigar a cinética de fotodegradação da tretinoína em loção, também foi investigada a extensão da isomerização da tretinoína em isotretinoína.

Percebe-se que dentre todas as técnicas cromatográficas mencionadas, considerando-se viabilidade de execução e obtenção de resultados satisfatórios, a CLAE em fase reversa é o método de escolha para análise dos retinóides, apresentando melhor desempenho do que a CLAE em fase normal (Gundersen, Blomhoff, 2001). Esta observação pode ser evidenciada pela Tabela I, a qual apresenta as várias técnicas de análises cromatográficas utilizadas para a detecção e determinação qualitativa e quantitativa dos retinóides, inclusive da isotretinoína.

\section{CONCLUSÕES E PERSPECTIVAS}

Apesar dos sérios efeitos adversos causados em alguns pacientes pelo uso de isotretinoína, este fármaco continua a ser a principal alternativa para o tratamento de acne cística severa, por apresentar grande eficácia na remissão dos nódulos e fístulas inflamatórias da acne.

No Brasil, o uso de isotretinoína está limitado ao tratamento dermatológico de acne vulgaris. Entretanto, em outros países, principalmente nos EUA, seu uso estendese ao tratamento de lesões neoplásicas como câncer de células basais, câncer de células escamosas e linfoma de células T (Wyatt et al., 2001).

De acordo com os resultados obtidos em diversos 
TABELA I - Técnicas de análise cromatográfica empregadas para a detecção e determinação qualitativa e quantitativa dos retinóides

\begin{tabular}{llllll}
\hline Matriz & Pré-coluna & Fase estacionária & Fase móvel (FM) & Detector & Referência \\
\hline Plasma & PEEK $^{\circledR}$ 20X4,0 mm, & Bondapak $^{\circledR}$ C18 & FM1a: ácido & Ultravioleta & Gundersen et al., \\
& Pelliguard C8 & $37-53 \mu \mathrm{m}$, Supplex & tetrafluoracético 0,05\%/ & $(\lambda=360 \mathrm{~nm})$ & 1997 \\
& $250 \times 4 \mathrm{~mm}$ & acetonitrila $(85: 15)$ & \\
& & FM1b :100\% metanol & \\
& & FM2:acetonitrila/1-butanol/ & \\
& & metanol/ acetato de amônio & \\
& & & \\
& & $(69: 2: 10: 16: 3)$ & \\
& & Acido acético glacial & \\
\end{tabular}

\begin{tabular}{|c|c|c|c|c|c|}
\hline $\begin{array}{l}\text { Forma } \\
\text { farmacêutica }\end{array}$ & Ausente & $\begin{array}{l}\text { Phenomenex } \\
\text { Prodigy }^{\circledR} 5 \mathrm{ODS}_{3}{ }^{\circledR} \\
(250 \times 3,2 \mathrm{~mm})\end{array}$ & $\begin{array}{l}\text { Acetonitrila/etanol/ácido } \\
\text { acético glacial } 1 \% \\
(68: 8: 24)\end{array}$ & $\begin{array}{l}\text { Fluorescência } \\
(\lambda \mathrm{em}=520 \mathrm{~nm}, \\
\lambda \mathrm{ex}=350 \mathrm{~nm})\end{array}$ & Gatti et al., 2000 \\
\hline Plasma & $\begin{array}{l}\text { Lichrocart }^{\circledR} \\
250 \times 4 \mathrm{~mm}\end{array}$ & $\begin{array}{l}\text { Lichrospher }{ }^{\circledR} \text { SI } 60 \\
(250 \times 4 \mathrm{~mm})\end{array}$ & $\begin{array}{l}\text { Hexano/diclorometano/ } \\
\text { dioxano contendo } 1 \% \text { de } \\
\text { ácido acético }(78: 18: 4)\end{array}$ & $\begin{array}{l}\text { Ultravioleta } \\
\lambda=360 \mathrm{~nm}\end{array}$ & $\begin{array}{l}\text { Lefebvre et al., } \\
1995\end{array}$ \\
\hline $\begin{array}{l}\text { Cápsula de } \\
\text { gelatina dura }\end{array}$ & $\begin{array}{l}\text { Lichrosorb }^{\circledR} \text { RP-18 } \\
(5 \mu \mathrm{m})\end{array}$ & $\begin{array}{l}\text { Lichrospher }{ }^{\circledR} 100 \\
\text { RP-18 }(5 \mu \mathrm{m})\end{array}$ & $\begin{array}{l}\text { Acetonitrila/acetato de } \\
\text { amônio } 1 \%(90: 10)\end{array}$ & $\begin{array}{l}\text { Ultravioleta-diode } \\
\text { array } \lambda=340 \mathrm{~nm} \\
\text { bandwidth } \\
4 \mathrm{~nm} / \text { referência } \\
\lambda=500 \mathrm{~nm} \\
\text { bandwidth } 80 \mathrm{~nm}\end{array}$ & $\begin{array}{l}\text { Caviglioli et al., } \\
1994\end{array}$ \\
\hline Plasma & $\begin{array}{l}\text { Presente } \\
\text { (não especificada) }\end{array}$ & $\begin{array}{l}\text { Lichrospher }^{(\mathbb{R}} 100 \\
\text { RP-18 }(5 \mu \mathrm{m}) \text {, } \\
\text { Superspher } 100 \\
\text { RP-18 }\end{array}$ & $\begin{array}{l}\text { FM1a: acetato de amônio } \\
10 \% / \mathrm{H}_{2} \mathrm{O} / \text { etanol/ácido } \\
\text { acético }(1: 7: 2: 0,1) ; \\
\text { FM1b: acetato de amônio } \\
10 \% / \mathrm{H}_{2} \mathrm{O} / \text { etanol/ácido } \\
\text { acético(1:9:0,4:0,2); } \\
\text { FM2a: acetato de amônio } \\
10 \% / \mathrm{H}_{2} \mathrm{O} / \text { ácido acético/ } \\
\text { acetonitrila }(6: 30: 1: 60) ; \\
\text { FM2b: acetato de amônio } \\
\text { 10\%/ } \mathrm{H}_{2} \mathrm{O} / \text { ácido acético/ } \\
\text { acetonitrila }(5: 20: 20: 950) ; \\
\text { FM2c: } \mathrm{H}_{2} \mathrm{O} / \text { ácido acético/ } \\
\text { acetonitrila }(5: 5: 990) ; \\
\text { FM3a: etanol/ } \mathrm{H}_{2} \mathrm{O} \text { e } \\
\text { FM3b: etanol }\end{array}$ & $\begin{array}{l}\text { Ultravioleta } \\
\lambda=230 \mathrm{~nm}\end{array}$ & $\begin{array}{l}\text { Wyss; Bucheli, } \\
1997\end{array}$ \\
\hline Plasma & Ausente & Nova Pak ${ }^{\circledR} \mathrm{C} 18$ & $\begin{array}{l}\text { FMa: metanol/acetonitrila/ } \\
\text { THF 5\% }(65: 35) \\
\text { FMb: ácido acético } \\
\text { aquoso } 2 \%\end{array}$ & $\begin{array}{l}\text { Ultravioleta } \\
\lambda=350 \mathrm{~nm}\end{array}$ & Disdier et al.,1996 \\
\hline
\end{tabular}


TABELA I - (continuação)

\begin{tabular}{|c|c|c|c|c|c|}
\hline Matriz & Pré-coluna & Fase estacionária & Fase móvel (FM) & Detector & Referência \\
\hline $\begin{array}{l}\text { Fármaco } \\
\text { (sólido) }\end{array}$ & $\begin{array}{l}\text { Presente } \\
\text { (não especificada) }\end{array}$ & $\begin{array}{l}\text { Hypersil }{ }^{\circledR} \text { ODS C18 } \\
(4,6 \times 15 \mathrm{~cm})\end{array}$ & $\begin{array}{l}\text { Acetonitrila/acetato de } \\
\text { amônio aquoso } 1 \%(95: 5)\end{array}$ & $\begin{array}{l}\text { Ultravioleta } \\
\lambda=280 \mathrm{~nm}\end{array}$ & Tan et al., 1992 \\
\hline $\begin{array}{l}\text { Fármaco } \\
\text { (sólido) }\end{array}$ & Ausente & $\begin{array}{l}\text { ZorbaxRx-Sil }{ }^{\circledR} \\
(25 \mathrm{~cm} \mathrm{x} \mathrm{4,6} \mathrm{mm)} \\
5 \mu \mathrm{m}\end{array}$ & $\begin{array}{l}\text { Heptano/THF/ácido } \\
\text { acético }(96,5: 3,5: 0,015)\end{array}$ & $\begin{array}{l}\text { Ultravioleta } \\
\lambda=365 \mathrm{~nm} \\
\text { EI espectro de } \\
\text { massa } 77 \mathrm{eV}, 200 \mathrm{~m} / \mathrm{z}\end{array}$ & $\begin{array}{l}\text { Bempong et al., } \\
1995\end{array}$ \\
\hline
\end{tabular}

\begin{tabular}{|c|c|c|c|c|c|}
\hline Plasma & Ausente & $\begin{array}{l}\text { Inertsil SILICA }^{\circledR} \\
100-5 \\
(4,6 \mathrm{~mm} \times 25 \mathrm{~cm})\end{array}$ & $\begin{array}{l}\text { FMa: } n \text {-hexano/2-propanol/ } \\
\text { ácido acético glacial } \\
(1000: 4,3: 0,675) \\
\text { FMb: } n \text {-hexano/2-propanol/ } \\
\text { ácido acético glacial } \\
(1000: 17,5: 0,675)\end{array}$ & $\begin{array}{l}\text { Ultravioleta } \\
\lambda=350 \mathrm{~nm}\end{array}$ & Miyagi et al., 2001 \\
\hline
\end{tabular}

\begin{tabular}{|c|c|c|c|c|c|}
\hline Plasma & Ausente & $\begin{array}{l}\text { Coluna C18 5mm } \\
(4,6 \mathrm{~mm} \times 25 \mathrm{~cm}) \\
\text { da Alltech }^{\circledR}\end{array}$ & $\begin{array}{l}\text { Metanol } / 0,1 \% \text { etanol e } \\
\text { trietilamina }(85: 15)\end{array}$ & $\begin{array}{l}\text { Ultravioleta } \\
\lambda=245 \mathrm{~nm}\end{array}$ & Po et al., 1997 \\
\hline Loção & $\begin{array}{l}\text { Lichrocart }^{\circledR} \\
(250 \times 4 \mathrm{~mm})\end{array}$ & $\begin{array}{l}\text { Lichrospher }^{\mathbb{B}} 100 \\
\text { RP-18 } 5 \mu \mathrm{m}\end{array}$ & $\begin{array}{l}\text { FMa: metanol/ } \mathrm{H}_{2} \mathrm{O} / \text { ácido } \\
\text { acético }(75: 12,5: 1) \\
\text { FMb acetonitrila/ } / \mathrm{H}_{2} \mathrm{O} / \text { ácido } \\
\text { acético }(80: 20: 1)\end{array}$ & $\begin{array}{l}\text { Ultravioleta } \\
\lambda=320-350 \mathrm{~nm}\end{array}$ & $\begin{array}{l}\text { Brisaert, Plaizier- } \\
\text { Vercammer, } 2000\end{array}$ \\
\hline
\end{tabular}

\begin{tabular}{|c|c|c|c|c|c|}
\hline $\begin{array}{l}\text { Cremes, géis e } \\
\text { cápsulas }\end{array}$ & Ausente & $\begin{array}{l}\text { Spherisorb ODS }{ }^{\circledR} 2 \\
(250 \times 4,6 \mathrm{~mm})\end{array}$ & $\begin{array}{l}\text { Metanol/acetonitrila/ácido } \\
\text { acético glacial } 0,05 \% \\
(42,5: 32,5: 25)\end{array}$ & $\begin{array}{l}\text { Ultravioleta } \\
\lambda=360 \mathrm{~nm}\end{array}$ & $\begin{array}{l}\text { Simmons et al., } \\
1997\end{array}$ \\
\hline Plasma & & $\begin{array}{l}\text { CG: } \mathrm{DB}^{\circledR}-5-30 \mathrm{~W} \\
(0,2 \mathrm{~mm} \times 20 \mathrm{~m})\end{array}$ & Hélio & $\begin{array}{l}\text { Detector seletivo } \\
\text { de massa }\end{array}$ & Eckhoff; Nau, 1990 \\
\hline $\begin{array}{l}\text { Pele humana } \\
\text { (extraida por } \\
\text { necrópsia) }\end{array}$ & & $\begin{array}{l}\text { CLAE 1: C18 } \\
\text { Resolve }^{\circledR} \text { (Watters) } \\
5 \mathrm{~mm} \times 15 \mathrm{~cm} \text { a } 25^{\circ} \mathrm{C} \\
\text { CLAE 2: C18 } \\
\text { Ultraspher }{ }^{\circledR} \text { (Altex) } \\
4,6 \mathrm{~mm} \times 25 \mathrm{~cm} \mathrm{a} 40{ }^{\circ} \mathrm{C} \\
\text { CG: DB-5-30W } \\
(0,2 \mathrm{~mm} \times 30 \mathrm{~m}) 3 \mathrm{~min} \\
\text { a } 180{ }^{\circ} \mathrm{C} \text { até } 220^{\circ} \mathrm{C}\end{array}$ & $\begin{array}{l}\text { FM1: metanol/acetonitrila/ } \\
\text { tampão aquoso }(2,5 \% \text { acetato } \\
\text { de amônio e } 0,1 \mathrm{M} \text { de ácido } \\
\text { maleico) }(50: 25: 25) \\
\text { FM2: :metanol/ } \mathrm{H}_{2} \mathrm{O} / \text { ácido } \\
\text { acético }(95: 4,5: 0,5) \\
\text { Hélio }\end{array}$ & $\begin{array}{l}\text { Ultravioleta } \\
\lambda=350 \mathrm{~nm} \\
\text { Ultravioleta } \\
\lambda=350-360 \mathrm{~nm} \\
\text { UV scan } 210-500 \mathrm{~nm} \\
\text { SIM m/e } 314 \text { EI mass } \\
\mathrm{m} / \mathrm{e} 40-400\end{array}$ & $\begin{array}{l}\text { Lehman; Malany, } \\
1989\end{array}$ \\
\hline
\end{tabular}


estudos de utilização dos retinóides, inclusive da isotretinoína, como promotores da diferenciação celular no tratamento de neoplasias (Sporn et al., 1976; Harisiadis et al., 1978; Lotan, 1980; Lotan et al., 1980; Breitman et al.,1981), estes fármacos apresentam grande potencial para aplicação clínica no tratamento de leucemias mielóide crônica, mielóide aguda e linfocítica. Prova disto é o crescente número de solicitações de registro de novos medicamentos junto ao FDA (Food and Drug Administration) para retinóides (por exemplo, ácido todo-transretinóico, ácido 9-cis-retinóico, bexaroteno) indicados para o tratamento de leucemia e, mais recentemente, para o tratamento do sarcoma de Kaposi relacionado à AIDS e ainda, para manifestações cutâneas de linfoma de células T. Dos produtos aprovados pelo FDA e que possuem registro na Agencia Nacional de Vigilância Sanitária (ANVISA), apenas a isotretinoína é comercializada no Brasil. A forma oral de tretinoína registrada pela ANVISA, teve registro cancelado em outubro de 2001 por solicitação do laboratório farmacêutico proprietário, estando liberada sua comercialização no Brasil sob as formas farmacêuticas de aplicação tópica.

Pode-se afirmar que não existe um único método que seja totalmente eficiente para a determinação analítica de todos os retinóides e seus isômeros. O que se tem observado é o emprego de várias metodologias analíticas para a separação e identificação do vasto número de retinóides naturais e sintéticos. A cromatografia líquida é sem dúvida alguma, o método mais difundido para a análise de retinóides o que, entretanto, não descarta o uso de técnicas de cromatografia gasosa que podem ser justificadas pelo conhecimento da estabilidade térmica destes compostos por técnicas analíticas de microcalorimetria e análise térmica.

Para garantir a estabilidade da isotretinoína frente a condições de manipulação, requisito indispensável para seu emprego em laboratórios farmacêuticos, é necessário o amplo conhecimento de suas propriedades físico-químicas e o desenvolvimento de métodos analíticos e operacionais de manipulação deste fármaco que possam proporcionar sua utilização segura e eficiente.

\section{ABSTRACT}

\section{Isotretinoin: pharmacological, pharmacokinetic and analytical profiles}

Isotretinoin, or 13-cis-retinoic acid, is one of the vitamin A related compounds. Isotretinoin is used for the treatment of severe cystic acne and also shows inhibitory activity over the proliferation of neoplasic cells, due to its efficiency in regulating cell diferentiation. Side effects are related to skin and mucous membranes, central nervous system, muscles, lymphatic, gastrintestinal, pulmonary and genitourinary systems. Isotretinoin is a highly thermal and photolabile compound. Stability studies require several analytical methods such as HPLC, GC, thermal analysis, mass spectrometry, microcalorimetry and X-Ray difratometry.

UNITERMS: Isotretinoin. HPLC. Stability. Therapeutic uses. Side effects.

\section{REFERÊNCIAS BIBLIOGRÁFICAS}

AHFS-DRUG INFORMATION. Skin and mucous membrane agents: miscellaneous skin and mucous membrane agents. Bethesda: AHFS, 1998. p. 2958-2963.

AL-KHAWAJAH, M. M. Isotretinoin for acne vulgaris. Int. J. Dermatol., Philadelphia, v.35, n. 3, p. 212-215, 1996.

ALLEN, J. G., BLOXHAM, D. P. The pharmacology and pharmacokinetics of the retinoids. Pharmac. Ther. Oxford, v. 40, n. 1, p. 1-27, 1989.

BARTH, J. H., MACDONALD-HUL, S. P., MARK, J., JONES, R. G., CUNLIFFE, W. J. Isotretinoin therapy for acne vulgaris: a re-evaluation of the need for measurements of plasma lipids and liver function tests. Br. J. Dermatol., Oxford, v. 129, n. 6, p. 704-707, 1993.

BEMPONG, D. K, HONIGBERG, I. L., MELTZER, N. M. Normal phase LC-MS determination of retinoic acid degradation products. J. Pharm. Biomed. Anal., Oxford, v.13, n. 3, p. 285-91, 1995.

BERBENNI, V., MARINI, A., CARDINI, A. Thermoanalytical and spectroscopic characterization of solid-state retinoic acid. Int. J. Pharm., Amsterdam, v. 221, n. 1-2, p. 123-41, 2001.

BIGBY, M. D., STERN, R. S. Adverse reactions to isotretinoin. A report from the Adverse Drug reaction reporting system. J. Am. Acad. Dermatol., Saint Louis, v. 18, n. 3, p. 543-552, 1988.

BOEHM, M. F., McCLURG, M. R., PATHIRANA, C., MANGELSDORF, D., WHITE, S. K., HEBERT, J., WINN, D., GOLDMAN, M. E., HEYMAN, R. A. Synthesis of high specific activity $\left({ }^{3} \mathrm{H}\right)-9$-cis-retinoic acid and its application for identifying retinoids with unusual binding properties. J. Med. Chem., Washington, v. 37, n. 3, p. 408-414, 1994. 
BOSCHETTI, C., PELLEGATTA, C., MAGNONE, R. On the isotretinoin manufactured by laboratori MAG. Milano: Laboratorio MAG,1996. 3p.

BRAND, N., PETKOVICH, M., KRUST, A., CHAMBON, P., MARCHIO, A., TIOLLAIS, P., DEJEAN, A. Identification of a second human retinoic acid receptor. Nature, London, v. 332. n. 6167, p. 850-853, 1988.

BRAZZELL, R. K., COLBURN, W. A. Pharmacokinetics of the retinoids isotretinoin and etretinate. J. Am. Acad. Dermatol., Saint Louis, v. 6, n. 4, pt 2 suppl., p. 643-651, 1982.

BREITMAN, T. R., COLLINS, S. J., KEENE, B. R. Terminal differentiation of human promyelocytic leukemia cells in primary culture in response to retinoic acid. Blood, New York, v. 57, n. 6, p. 1000-1004, 1981.

BRISAERT, M., PLAIZIER-VERCAMMEN, J. Investigation on the photostability of a tretinoin lotion and stabilization with additives. Int. J. Pharm., Amsterdam, v. 199, n.1, p. 49-57, 2000.

BULENGO-RANSBY, S. M., GRIFFITHS, C. E. M., KIMBROUGH-GREEN, C. K., FINKEL, L. J., HAMILTON, T. A., ELLIS, C. N., VOORHEES, J. J. Topical tretinoin (retinoic acid) therapy for hyperpigmented lesions caused by inflammation of the skin in black patients. N. Engl. J. Med., Waltham, v. 328, n. 20, p. 1438-1443, 1993.

CAVIGLIOLI, G., PARODI, B., CAFFAGI, S., BIGNARDI, G., ROMUSSI, G. Stability indicating HPLC assay for retinoic acid in hard gelatine capsules containing lactose and as bulk drug substance. Drug. Dev. Ind. Pharm., New York, v. 20, n. 15, p. 1295-1408, 1994.

CHANDRARATNA, R. A. S. Tazarotene, first of a new generation of receptor selective retinoids. Br. $J$. Dermatol., Oxford, v. 135, suppl 49, p. 18s-25s, 1996.

DISDIER, B., BUN, H., CATALIN, J., DURAND, A. Simultaneous determination of all-trans-, 13-cis, 9-cisretinoic acid and their 4-oxo-metabolites in plasma by high performance liquid chromatography. J. Chromatogr. B., Amsterdam, v. 683, n. 2, p.143-154, 1996.
DUESTER, G. Involvement of alcohol dehydrogenase, Short-Chain dehydrogenase/redutase, aldehyde dehydrogenase, and cytochrome P450 in the control of retinoid signaling by activation of retinoic acid synthesis. Biochemistry, New York, v.35, n. 38, p. 12221-12227.

DRUGDEX - DRUG EVALUATIONS. Isotretinoin. Disponível em: http://www. cdrompro.com.br/ufg. Acesso em: 26 mar 2001.

ECKHOFF, C.; NAU, H. Identification and quantitation of all-trans- and 13-cis-retinoic acid and 13-cis-4oxoretinoic acid in human plasma. J. Lipid. Res., Bethesda, v.31, n.8, p. 1445-1454, 1990.

FARREL, L. N., STRAUSS, J. S., STRANIERI, A. M. The treatment of severe cystic acne with 13-cis-retinoic acid. Evaluation of sebum production and clinical response in a multiple-dose trial. J. Am. Acad.Dermatol., Saint Louis, v.3, n.6, p.602-611, 1980.

FDA (U. S. Food and Drug Administration ) - FDA Oncology tools approval summary for tretinoína, ATRA for induction of remission in patients with acute promyelocitic leukemia(APL) who are refractory to or unable to tolerate anthracycline based cytotoxic chemotherapeutic regimes. Disponível em: $<$ http:// www.acessdata.fda.gov/scripts/cder $>$. Acesso em: agosto 2002.

FONSECA, A., PRISTA, L. N. Manual de terapêutica dermatológica e cosmetologia. São Paulo: ROCA, 1993. p. 129, 273.

FUNK, C. (1912) J. State. Med. 20, 341-368 Apud Nomenclature of retinoids. IUPAC-IUB Joint Commission on Biochemical Nomenclature (JCBN). $J$. Biol. Chem., Berlin, v. 258, n. 9, p. 5329-5333, 1983. Verificar

FUNK, C. (1912) J. State. Med. 20, 341-368 Apud Nomenclature of retinoids. IUPAC-IUB Joint Commission on Biochemical Nomenclature (JCBN). . Arch. Biochem. Biophys., New York, v. 224, n. 2, p. 728 731, 1983. Verificar

GATTI, R., GIOIA, M. G., CAVRINI, V. Analysis and stability study of retinoids in pharmaceuticals by fluorescence detection. J. Pharm. Biomed. Anal., Oxford, v.23, n. 1, p. 147-159, 2000. 
GATTI, R., GIOIA, M. G.; DI PIETRA, A. M.; CINI, M. Determination of retinoids in galenicals by column liquid chromatography with fluorescence and diode-array detection, J. Chromatogr. A., Amsterdam, v.905, n. 1-2, p.345-50, 2001.

GIGUERE, V., ONG, E. S., SEGUI, P., EVANS, R. M. Identification of a receptor for the morphogen retinoic acid. Nature., London., v. 330, n. 6149, p. 624-629, 1987.

GUNDERSEN, TH. E., LUNDANES, E., BLOMHOFF, R. Quantitative high-performance liquid chromatographic determination of retinoids in human serum using on-line solid-phase extraction and column switching. Determination of 9-cis-retinoic acid, 13-cis-retinoic acid, all-trans-retinoic acid, 4-oxo-all-trans-retinoic acid and 4-oxo-13-cis-retinoic acid. J. Chromatogr. B., Amsterdam, v. 691, n. 1, p. 43-58, 1997.

GUNDERSEN, TH. E., BLOMHOFF, R. Qualitative and quantitative liquid chromatography determination of natural retinoids in biological sample. J. Chromatogr. A., Amsterdam, v. 935, n. 1-2, p. 13-43, 2001.

HARISIADIS, L. R., MILLER, R. C., HALL, E. J., BOREK, C. A vitamina A analog inhibits radiation-induce oncogenic transformation. Nature, London, v. 274, n. 3, p. 486-487, 1978.

HEYMAN, R. A., MANGELSDORF, D. J., DYCK, J. A.. STEIN, R.B., EICHELE, G., EVANS, R. M., THALLER, C. 9-Cis retinoic acid is a high affinity ligand for the retinoid X receptor. Cell, Massachusetts, v. 68, n.2, p. 397-406, 1992.

HOMMEL, L., GEIGER, J. M., HARMS, M., SAURAT, J. H. Sebum excretion rate in subjects treated with oral alltrans-retinoic acid. Dermatology, Basel, v. 193, n.2, p. 127-130, 1996

IUPAC-IUB. Commission on Biochemical Nomenclature (CBN). Tentative rules, section on Trivial names of micellaneous compounds of importance in Biochemistry. J. Biol.Chem., Berlin, v. 241, n.11, p. 2987-2988, 1966.

IUPAC-IUB Joint Commission on Biochemical Nomenclature (JCBN). Nomenclature of retinoids. $J$. Biol.Chem., Berlin, v. 258, n.9, p. 5329-5333, 1983.
KARRER, P., MORF, R., SCHOEPP, K. (1931). Helv. Chim. Acta 21, 211-222 Apud Nomenclature of retinoids. IUPAC-IUB Joint Commission on Biochemical Nomenclature (JCBN). J. Biol. Chem.,Berlin, v. 258, n. 9, p. 5329-., Berlin, v. 258, n. 9, p. 5329-.; SCHOEPP, K. (1931). Helv. Chim. Acta 21, 211-222 Apud Nomenclature of Retinoids. IUPAC-IUB Joint Commission on Biochemical Nomenclature (JCBN). Arch. Biochem. Biophys, New York, v. 224, n. 2, p. 728 731, 1983. Verificar

KITAREEWAN, S., BURKA, L. T., TOMER, K. B., PARKER, L. J., DETERDING, L. J., STEVENS, R. D., FORMAN, B. M., MAIS, D. E., HEYMAN, R. A., McMORRIS, T., WEINBERGER, C. Phytol metabolites are circulating dietary factors that activate the nuclear receptor RXR. Mol. Biol. Cell, Massachusetts,v. 7, n. 8, p. 1153-1166, 1996.

KLAASSEN, I., BRAKENHOFF, R. H., SMEETS, S. J., SNOW, G. B., BRAAKHUIS, B. J. M. Considerations for in vitro retinoid experiments: importance of protein interaction. Biochim. Biophys. Acta, Amsterdam, v.1427, n.2, p. 265-75, 1999.

LABORATORIO MAG (Milano, Itália). Ângelo Magnone Grato. Process for the preparation of 13-cis-retinoic acid. USA MI98A1093, May 19, 1998, May 17, 1999. Disponível em: $<$ http:// pattt. uspto.gov/netacgi>. Acesso em: 22 Jan, 2002.

LEBOWITZ, M., BERSON, D. S. Ocular effects of oral retinoids. J. Am. Acad. Dermatol., Saint Louis, v. 19, n. 1, p. 209-211. 1988

LEFEBVRE, P., AGADIR, A., CORNIC, M., GOURMEL, B., HUE, B., DREUX, C., DEGOS; L., CHOMIENNE, C. Simultaneous determination of all trans and 13-cis retinoic acids and their 4-oxo-metabolites by absorption liquid chromatography after solid phase extraction. J. Chromatogr. B., Amsterdam, v. 666, n.1, p. 55-61, 1995.

LEHMAN, P. A., FRANZ, T. J. A. sensitive high-pressure liquid chromatography/ particle beam/ mass spectrometry assay for the determination of all-transretinoic acid and 13-cis-retinoic acid in human plasma. J. Pharm. Sci., Washington, v. 85, n.3, p. 287-90, 1996. 
LEHMAN, P.A., MALANY, A. M. Evidence for percutaneous absorption of isotretinoin from the photoisomerization of topical tretinoin. J. Invest. Dermatol., Baltimore, v. 93,n.5, p.595-599, 1989.

LEVIN, A. A., STURZENBECKER, L. J.; KAZMER, S., BOSAKOWSKI, T., HUSELTON, C., ALLENBY, G., SPECK, J., KRATZEISEN, C. I., ROSENBERGER, M., LOVEY, A., GRIPPO, J. F. 9-Cis retinoic acid stereoisomer binds and activates the nuclear recepor RXRa. Nature., London, v. 355, n.6358, p.359-361, 1992.

LOTAN, R. Effects of vitamin A and its analogs (retinoids) on normal and neoplastic cells. Biochem. Biophys. Acta, Amsterdam, v. 605, n. 1, p. 33-91, 1980.

LOTAN, R., ONG, D. E., CHYTIL, F. Comparison of the level of cellular retinoic-binding proteins and susceptibility to retinoid induced growth inhibition of various neoplastic cell lines. J. Natl. Cancer. Inst., Bethesda, v. 64, n. 5, p. 1259-1262, 1980.

MALPEZZI, L., BOSCHETTI, C., FUGANTI, C., GRASSELLI, P., MAGNONE, G.A., PELLEGATTA, C. Stability of 13-cis-retinoic acid an x-ray diffraction study. Pharm. Ind., Postfach., v. 60, n. 11, p. 983-985. 1998.

MANGELSDORF, D. J., ONG, E. S., DYCK, J. A., EVANS, R. M. Nuclear receptor that identifies a novel retinoic acid response pathway. Nature., London., v. 345, n.6272, p. 224-229, 1990.

MANGELSDORF, D. J., UMESONO, K., KLIEWER, S. A., BORGMEYER, U., ONG, E. S., EVANS, R. M. A direct repeat in the cellular retinol-binding protein type II gene confers differential regulation by RXR and RAR. Cell, Massachusetts, v. 66, n.3, p. 555-561, 1991.

MANGELSDORF, D. J., EVANS, R.M. The RXR heterodimers and orphan receptors. Cell, Massachusetts, v. 83, n.6, p. 841-850, 1995.

MARCUS, R., COULSTON, A. M. Fat-Soluble Vitamins In: HARDMAN, J.G., GOODMAN GILMAN, N.A., LIMB IRD, L.E., eds. Goodman \& Gilman's: the pharmacological basis of therapeutics. 9. ed. New York: Mc Graw Hill, 1996. p. 617-657.
MARCUS, R., COULSTON, A. M. Fat-Soluble Vitamins In: HARDMAN, J.G., GOODMAN GILMAN, N.A., LIMB IRD, L.E. Goodman \& Gilman's: The Pharmacological Basis of Therapeutics. 10. ed. New York: Mc Graw Hill, 2001. p. 1773-1791.

MARTINDALE. The Extra Pharmacopeia. 13. ed. London: Royal Pharmaceutical Society, 1996. p. 1087-1089.

McCARTER, T. L., CHEN, Y. K. Marked hyperlipidemia and pancreatitis associated with isotretinoin therapy. Am. J. Gastroenterol., Baltimore, v. 87, n. 12, p. 1855-8, 1992.

McCOLLUM, E. V., KENNEDY, C. (1916). J. Biol. Chem. 24, 491-502 Apud Nomenclature of Retinoids. IUPACIUB Joint Commission on Biochemical Nomenclature (JCBN). J. Biol. Chem., Berlin, v. 258, n. 9, p. 5329-5333, 1983. Verificar

McCOLLUM, E. V., KENNEDY, C. (1916). J. Biol. Chem. 24, 491-502 Apud Nomenclature of Retinoids. IUPACIUB Joint Commission on Biochemical Nomenclature (JCBN). Arch. Biochem. Biophys., New York, v. 224, n. 2, p. 728-731, 1983.

MIYAGI, M., YOKOYAMA, H., SHIRAISHI, H., MATSUMOTO, M., ISHII, H., Simultaneous quantification of retinol, retinal, and retinoic acid isomers by high-performance liquid chromatography with a simple gradiation. J. Chromatogr. B. Biomed. Sci. Appl., Amsterdam, v. 757, n.2, p. 365-8, 2001.

MORTOM, R.A. (1944), Nature (London) 153, 69-71 apud Nomenclature of Retinoids. IUPAC-IUB Joint Commission on Biochemical Nomenclature (JCBN). $J$. Biol. Chem., Berlin, v. 258, n. 9, p. 5329-5333, 1983

MORTOM, R.A. (1944), Nature (London) 153, 69-71 Apud Nomenclature of Retinoids. IUPAC-IUB Joint Commission on Biochemical Nomenclature (JCBN). Arch. Biochem. Biophys., New York, v. 224, n. 2, p. 728 $731,1983$.

MORTOM, R. A.; GOODWIN, T. W. (1944), Nature (London) 153, 405-406 Apud Nomenclature of Retinoids. IUPAC-IUB Joint Commission on Biochemical Nomenclature (JCBN). J. Biol. Chem., Berlin, v. 258, n. 9, p. 5329-5333, 1983. 
MORTOM, R. A.; GOODWIN, T. W. (1944), Nature (London) 153, 405-406 Apud Nomenclature of Retinoids. IUPAC-IUB Joint Commission on Biochemical Nomenclature (JCBN). Arch. Biochem. Biophys., New York, v. 224, n. 2, p. 728-731, 1983.

NAGPAL, S., ATHANIKAR, J., CHANDRARATNA, R. S. A. Separation of trans-activation and AP1 antagonism functions of retinoic acid receptor a. J. Biol. Chem., Berlin, v.270, n.,p.923-927, 1995.

NANKERVIS, R., DAVIS, S. S., DAY, N. H., SHAW, P. N. Effect of lipid vehicle on intestinal lymphatic transport of isotretinoin in the rat. Int. J. Pharm., Amsterdam, v. 119, n. 2, p. 173-181,1995.

NAPOLI, J. L. Interactions of retinoid binding proteins and enzymes in retinoid metabolism. Biochim. Biophys. Acta., Amsterdam, v. 1440, n. 2-3, p. 139-62, 1999.

OLIVEIRA, E. J., WATSON, D. G. Chromatographic techniques for the determination of putative dietary anticancer compounds in biological fluids. $J$. Chromatogr. B. Biomed. Sci. Appl., Amsterdam, v.764, n.1-2, p.3-25, 2001.

ORGANIZACIÓN MUNDIAL DE LA SALUD. Acne vulgar. In: Modelo OMS de información sobre prescripción de medicamentos: Medicamentos utilizados en las enfermedades cutaneas. Genebra: OMS, 1999. p. 59-63.

OYLER, A. R., MOTTO, M. G., NALDI, R. E., FACCHINE, K. L., HAMBURG, P. F., BURINSKY, D. J., DUNPHY, R., COTTER, M. L. Characterization of autoxidation products of retinoic acid. Tetrahedron., Oxford, v. 45, n. 24, p. 7679-694, 1989.

PARTHASARATHY, R., MEHTA, K. Altered metabolism of all-trans-retinoic acid in liposome-encapsulated form. Cancer Lett., Amsterdam, v. 134, n.2, p. 121-8,1998.

PETKOVICH, M., BRAND, N. J., KRUST, A., CHAMBON, P. A human retinoic acid receptor which belongs to the family of nuclear receptors. Nature, London, v. 330, n. 6147, p. 444-450, 1987.

PO, E. S. M, HO, J. W, GONG, B. Y. Simultaneous chromatography analysis of eight fat-soluble vitamins in plasma. J. Biochem. Biophys. Meth., Amsterdam, v.34, p.99-106, 1997.
ROCHE Pharmaceuticals. Vesanoid (tretinoína). Disponível em: $<$ http://www.rocheusa.com/products $>$. Acesso em: agosto 2002 .

SAKHI, A. K., GUNDERSEN, T. E., ULVEN, S. M., BLOMHOFF, R., LUNDANES, E. Quantitative determination of endogenous retinoids in mouse embryos by high-performance liquid chromatography with on-line solid-phase extraction, column switching and electrochemical detection. J. Chromatogr. A., Amsterdam, v.18, n. 828 (1-2), p. 451-60, 1998.

SAURAT, J.H. Oral isotretinoin. Where now, where next? Dermatology, Basel, v. 195, n. 1, p. 1-3, 1997.

SIMMONS, B. R., CHUKWUMERIJE, O., STEWART, J. T. Supercritical fluid extraction of 13-cis retinoic acid and its photoisomers from selected pharmaceutical dosage forms. J. Pharm. Biomed. Anal., Oxford, v. 16, p. 395403, 1997.

SINGH, S., BAKSHI, M. Guidance on conduct of stress tests to determine inherent stability of drugs. Pharm. Tech. on line, Eugene, p.1-14, Abril 2000. Disponível em: $<$ www.pharmaportal.com>

SPORN, M. B., DUNLOP, N. M., NEWTON, D. L., SMITH, J. M. Prevention of chemical carcinogenesis by vitamina A and its synthetic analogs (retinoids). Federation Proceedings., Bethesda, v. 35, n. 6, p. 13321338, 1976.

SPORN, M. B, ROBERTS, A. B. What is a retinoid? In: Retinoids differentiation and disease. Ciba Found Symp. v.113, p. 1-5, 1985.

STAM, C. H. (1972) Acta Crystallogr B 28, 2936-2945 Apud BERBENNI, V. et al., Thermoanalytical and spectroscopic characterization of solid-state retinoic acid. Int. J. Pharm., Amsterdam, v. 221, n. 1-2, p. 123-41, 2001.

STAM, C. H., McGILLAVRY, C. H. (1963) Acta Crystallogr. 16, 62-68 Apud BERBENNI, V. et al., Thermoanalytical and spectroscopic characterization of solid-state retinoic acid. Int. J. Pharm., Amsterdam, v. 221, n. 1-2, p. 123-41, 2001. 
TAN, X., MELTZER, N., LINDENBAUM, S. Solid-state stability studies of 13-cis retinoic acid and all trans retinoic acid using microcalorimetry and HPLC analysis. Pharm. Res., New York, v. 9, n. 9, p. 1203-1208, 1992.

TAN, X., MELTZER, N., LINDENBAUM, S. Determination to the kinetics of degradation to 13-cisretinoic acid and all-trans retinoic acid in solution. $J$. Pharm. Biomed. Anal., Oxford, v. 11, n. 9. p. 817-822, 1993.

TOLMAN, E. L. Acne and Acneiform Dermatoses. In: MOSCHELlA, S. L., HURLEY, H. J., eds. Dermatology. 3. ed. Philadelphia: W. B. Saunders, C 1992. v. 2, p. 1477-1491.

UMESONO, K., GIGUERE, V., GLASS, C. K., ROSENFELD, M. G., EVANS, R. M. Retinoic acid and thyroid hormone induce gene expression through a common responsive element. Nature., London, v. 336, n. 6196, p. 262-265, 1988.

WALD, G. (1934). Nature (London) 134, 65 apud Nomenclature of Retinoids. IUPAC-IUB Joint Commission on Biochemical Nomenclature (JCBN). $J$. Biol. Chem., Berlin, v. 258, n. 9, p. 5329-5333, 1983. Arch. Biochem. Biophys., New York, v. 224, n. 2, p. 728$731,1983$.

WANG, L. H., WANG, J. F. Determination of retinoids in human serum, tocopherol and retinyl acetate in pharmaceuticals by RP-LC with electrochemical detection. J. Pharm. Biomed. Anal., Oxford, v. 25, n. 56, p. 785-93, 2001.
WARREL, R. P., FRANKELL, W. H., MILLER JR., W. H., SCHEINBERG, D. A., ITRI, L. M., HITTELMAN, W. N., VYAS, R., ANFREEF, M., TAFURI, A., JAKUBOWSKI, J., GABRILOVE, J., GORDON, M., DMITROVSKY, E. Differentiation therapy of acute promyelocytic leukemia with tretinoin (all-trans-retinoic acid). N. Engl. J. Med., Waltham, v.324, n. 20, p. 13851393, 1991.

WHITE, G. M. Acne therapy. Disease-a-month. v. 45, n. 8 , p. 301-332, 1999.

WYATT, E. L., SUTTER, H. S., DRAKE, L. A. Dermatological Pharmacology In: HARDMAN, J. G., GOODMAN GILMAN, N. A., LIMB IRD, L. E., eds., Goodman \& Gilman's: the pharmacological basis of therapeutics. 10. ed., New York: Mc Graw Hill, 2001. p. 1795-1818.

WYSS, R., BUCHELI, F. Quantitative analysis of retinoids in biological fluids by high-performance liquid chromatography using column switching - III Determination of the arotinoid sumarotene and its Zisomer in human and animal plasma. J. Chromatogr. B., Amsterdam, v. 576, n.1, p. 111-120, 1992

WYSS, R., BUCHELI, F. Determination of endogenous level of 13-cis-retionoic acid (isotretinoin) all-trans-retinoic acid (tretinoin) and their 4-oxo-metabolites in human and animal plasma by high performance liquid chromatography with automated column switching and ultraviolet detection, J. Chromatogr. B., Amsterdam, v. 700, n. 1-2, p. 31-47, 1997.

Recebido para publicação em 27 de março de 2002. 